\title{
Correction to: Use of oral anticoagulant drugs is associated with carotid intraplaque hemorrhage in atherosclerosis patients: a meta-analysis
}

\author{
Xin Cao ${ }^{1}$. Jun Zhang ${ }^{1,2} \cdot$ Daoying Geng ${ }^{1,2}$
}

Published online: 14 May 2019

(c) Springer Science+Business Media, LLC, part of Springer Nature 2019
Nature 2019 and the article is forthwith distributed under the terms of copyright.

Publisher's Note Springer Nature remains neutral with regard to jurisdictional claims in published maps and institutional affiliations.
Jun Zhang

zhj81828@163.com

$\triangle$ Daoying Geng

gdy_2019@163.com

Xin $\mathrm{Cao}$

13262566515@163.com

1 Department of Radiology, Huashan Hospital, Fudan University, No. 12 Wulumuqi Road (Middle),

Shanghai 200040, China

2 Institute of Functional and Molecular Medical Imaging, Fudan University, No. 12 Wulumuqi Road (Middle),

Shanghai 200040, China 